\title{
HUBUNGAN QUALITY OF WORK LIFE (QWL) TERHADAP KINERJA DOKTER DI RSUD SYEKH YUSUF KABUPATEN GOWA
}

\section{QUALITY OF WORK LIFE (QWL) AND ITS RELATION TO PHYSICIAN'S WORK PERFORMANCE IN PUBLIC REGIONAL HOSPITAL OF SYEKH YUSUF KABUPATEN GOWA}

\author{
Putra Imanullah ${ }^{1}$, Syahrir A. Pasinringi ${ }^{1}$, Ansariadi $^{2}$ \\ ${ }^{I}$ Bagian Manajemen Rumah Sakit, Fakultas Kesehatan Masyarakat, Universitas Hasanuddin \\ ${ }^{2}$ Bagian Epidemiologi, Fakultas Kesehatan Masyarakat, Universitas Hasanuddin
}

\author{
Alamat Korespondensi: Putra Imanullah, Fakultas Kesehatan Masyarakat, Universitas \\ Hasanuddin Makassar, Telp: 08218751003, Email: \\ putraimanullah@gmail.com
}

\begin{abstract}
Abstrak
Quality or Work Life (QWL) adalah persepsi karyawan terhadap kehidupan kerja yang dapat mempengarı kinerja individu baik secara langsung maupun tidak langsung. Penelitian ini bertujuan untuk menganalisıs hubungan QWL beserta dimensinya terhadap kinerja dokter di RSUD Syekh Yusuf Kabupaten Gowa. Penelitian dilaksanakan di RSUD Syekh Yusuf Kabupaten Gowa. Jenis penelitian yang digunakan adalah cross sectional dengan menggunakan mixed method (metode kualitatif dan kuantitatif). Pengambilan sampel pada penelitian ini dilakukan menggunakan metode total sampling terhadap 44 dokter dan dokter gigi yang bertugas. Analisis yang digunakan adalah Fisher dan regresi logistik. Hasil penelitian menggunanakan analisis bivariat menunjukan bahwa variabel yang memiliki hubungan signifikan dengan kinerja adalah quality of work life $(\mathrm{p}=0,000)$, kompensasi yang seimbang $(0,001)$, rasa aman terhadap pekerjaan $(\mathrm{p}=0,032)$, keselamatan lingkungan kerja $(\mathrm{p}=0,027)$ dan rasa bangga terhadap institusi $(\mathrm{p}=0,048)$. Sedangkan variabel keterlibatan dokter, pengembangan karir $(p=0,247)$, fasilitas yang tersedia $(p=0,161)$, penyelesaian masalah $(p=0,175)$, dan komunikasi $(p=0,105)$ tidak memiliki hubungan signifikan terhadap kinerja dokter. Selanjutnya, dari seluruh komponen QWL, kompensasi merupakan variabel yang paling berpengaruh terhadap kinerja dokter $(B=3,133 \mathrm{p}=0,009)$. Suasana ideal yang dapat meningkatkan kinerja dokter ialah harus didukung dengan sarana dan prasana yang baik, dijembatani dengan komunikasi yang baik dan kebijakan-kebijakan yang paten serta tersosialisasi dengan baik.
\end{abstract}

Kata Kunci: Quality of Work Life, Kinerja, Dokter, Dokter Gigi

\begin{abstract}
Quality or Work Life (QWL) is employee's perception on their work life that contributes to the employee's job performance. The aim of this study was to analyze the relationship between quality of work life and its components to physician's work performance in Public Regional Hospital of Syekh Yusuf Kabupaten Gowa. This research was conducted at Public Regional Hospital of Syekh Yusuf Kabupaten Gowa. This research used cross sectional study using mixed method approach (qualitative and quantitative method). This study used total sampling of 44 physicians and dentists. The analysis of the study used Fisher and logistic regression. The results of this study indicate that quality of work life $(p=0,000)$, equitable compensation $(0,001)$, job security $(p=0,032)$, safe environment $(p=0,027)$ and pride $(p=0,048)$ have significant relation to physician's work performance. While career development $(p=0,247)$, wellness $(p=0,161)$, conflict resolution $(p=0,175)$, and communication $(p=0,105)$ have no significant relation to physician's work performance. Out of all components of $Q W L$, equitable compensation has the most influential effect on physician's job performance $(\mathrm{B}=3,133 \mathrm{p}=0,009)$. The ideal work environment to enhance physician's work performance must be supported by standardized facilities, good communication, as well as firm and well-socialized rules.
\end{abstract}

Keywords: Quality Of Work Life, Work Performance, Physician, Dentist 


\section{PENDAHULUAN}

Sebagai pemberi pelayanan kesehatan utama, kinerja dokter memiliki peran besar dalam mewujudkan pelayanan kesehatan perorangan yang bermutu. Selain memiliki kewajiban kepada pasien, dokter juga memiliki peran penting sebagai pemimpin klinis dalam mempengaruhi tim pemberi pelayanan lainnya. Pemimpin klinis adalah dokter yang melakukan peran sebagai klinisi dan pada saat yang bersamaan, juga berpartisipasi dalam manajemen, termasuk pengelolaan sumber daya (Pratama. 2012).

Untuk dapat memberikan pelayanan yang baik dan profesional perlu ditumbuhkan budaya kerja yang baik. Budaya kerja akan mampu muncul dalam kinerja seorang karyawan jika mereka mempunyai dasar nilai-nilai yang baik dan luhur yang didorong oleh suatu lingkungan kerja yang kondusif. Menurut Hariyanti (2012) pihak manajemen perlu untuk membuat karyawan merasa nyaman dengan pekerjaan dan lingkungannya sehingga mereka dapat mencapai kinerja terbaik. Hal tersebut didukung oleh Buller (1995) yang mengemukakan bahwa kesuksesan organisasi dapat dilihat melalui partnership yang baik antara sumberdaya manusia dan perencanaan strategis yang dilakukan oleh organisasi.

Gibson \& Donnelly dikutip dalam artikel ilmiah oleh Rai dan Tripathi (2015) meyakini bahwa kinerja organisasi bergantung pada kinerja individu. Kinerja itu sendiri adalah hasil evaluasi terhadap pekerjaan yang dilakukan individu dibandingkan dengan kriteria yang telah ditetapkan bersama (Robbins, 2002). Dalam penelitiannya, Pratama (2012) mengemukakan bahwa kinerja rumah sakit sebagai suatu unit pelayanan kesehatan dapat dinilai dengan membandingkan kinerja aktual para pegawainya dengan standar yang ditetapkan.

Tingkat kinerja karyawan pada suatu organisasi bersifat multifaktorial (Campbell, 1990). Faktor-faktor yang mempengaruhi kinerja antara lain komitmen organisasi, quality of work life (QWL), motivasi kerja, perilaku individu, dan kepuasan kerja. Hal tersebut telah banyak mendapat perhatian dan diteliti oleh Rai dan Tripathi (2015), Pratama
(2012), Simanungkalit (2012), Aketch (2012), Samtica (2011), dan Husnawati (2006). Cascio (2006) mendefinisikan QWL sebagai persepsi karyawan akan kesejahteraan mental dan fisik di tempat kerja. Model Quality of Work Life QWL terdiri atas Sembilan komponen, yaitu: kompensasi, pengembangan karir, keselamatan lingkungan kerja, komunikasi, keterlibatan karyawan, penyelesaian masalah, fasilitas yang tersedia, rasa bangga terhadap institusi, dan rasa aman terhadap pekerjaan (Cascio, 2006).

Rumah Sakit Syekh Yusuf Kabupaten Gowa merupakan rumah sakit milik pemerintah daerah kelas B non pendidikan (Profil RSUD Syekh Yusuf, 2015). Rumah sakit kelas B adalah rumah sakit yang mampu memberikan pelayanan kedokteran spesialis dan subspesialis terbatas. Rumah sakit ini diharapkan mampu memberikan pelayanan kesehatan yang bermutu dan dituntut untuk memaksimalkan segala sumber daya yang dimiliki untuk memperoleh kinerja yang maksimal. Berdasarkan survei pendahuluan pada hasil monitoring dan evaluasi Standar Pelayanan Minimal Rumah Sakit (SPM-RS) pada tahun 2016. Dari 22 pelayanan yang dinilai, terdapat lima pelayanan yang berkaitan langsung dengan kinerja dokter, namun empat dari tujuh indikator di dalamnya belum memenuhi standar. Sehingga capaian kinerja dokter pada tahun 2016 hanya 42,85\% (standar $100 \%)$.

Oleh karena itu dalam upaya meningkatkan kinerja individu perlu dilakukan identifikasi faktor yang mempengaruhi, kemudian diimplementasikan dalam sistem manajemen sumber daya manusia yang berpihak pada karyawan, dinamis dan solutif serta berkelanjutan guna meningkatkan dan menjaga tingkat kinerja karyawan (Purnawanto, 2010). Penelitian ini ditujukan untuk memperoleh informasi mengenai hubungan quality of work life (QWL) dan komponennya terhadap kinerja dokter serta hal-hal yang mempengaruhi QWL dan kinerja dokter di RSUD Syekh Yusuf Kabupaten Gowa. 


\section{BAHAN DAN METODE}

\section{Lokasi dan Rancangan penelitian}

Penelitian ini telah dilaksanakan di RSUD Syekh Yusuf Kabupaten Gowa. Jenis penelitian yang digunakan adalah mixed method. Penelitian kuantitatif dilakukan menggunakan desain cross sectional study, sementara pendekatan kualitatif dilakukan menggunakan strategi sequential explanatory dengan rancangan cross sectional study.

\section{Populasi dan sampel}

Populasi penelitian ini adalah semua dokter, dokter gigi dan dokter spesialis yang melakukan pelayanan medis di RSUD Syekh Yusuf Kabupaten Gowa sebanyak 44 orang. Pengambilan sampel dilakukan dengan cara total sampling.

\section{Metode pengumpulan data}

Pengumpulan data kuantitatif dilakukan menggunakan kuesioner. Instrumen kuesioner ini merupakan kuesioner terstruktur yang terdiri atas dua bagian yaitu bagian pertama terdiri atas pertanyaan demografi, dan bagian kedua terdiri atas 46 pernyataan untuk mengukur aspek QWL yang dibagi menjadi sembilan bagian sesuai dengan komponennya (Cascio, 2006). Sementara penilaian kinerja dokter dilakukan dengan metode peer evaluation menggunakan kuesioner yang terdiri atas 11 pernyataan (ACGME, 1999). Jawaban dari seluruh variabel kemudian diberi skor antara 1-4 dengan pilihan jawaban dari "sangat tidak setuju" hingga "sangat setuju" menggunakan skala likert. Sedangkan pada penelitian kualititatif instrumen utama adalah peneliti sendiri dengan menggunakan pedoman wawancara semiterstruktur (in-depth interview) terkait variabel penelitian.

\section{Analisis data}

Data yang telah terkumpul selanjutnya dianalisis secara kuantitatif dengan mengunakan statistik deskriptif atau inferensial sehingga dapat disimpulkan hipotesis yang dirumuskan terbukti atau tidak (Sugiyono, 2012). Teknik analisis data yang digunakan adalah analisis univariat, yang berfungsi memberikan gambaran karakteristik populasi dan penyajian hasil deskriptif melalui frekuensi dan distribusi dari variabel bebas dan variabel terikat. Analisis bivariat, dilakukan untuk mencari ada tidaknya hubungan variabel bebas dengan variabel terikat dengan menggunakan uji Fisher. Analisis multivariat, dilakukan untuk melihat pengaruh dan arah variabel bebas terhadap variabel terikat dengan menggunakan analisis regresi logistik. Sedangkan Analisis data kualitatif dilakukan secara kualitatif deskriptif dengan memperoleh data / informasi dari responden dan selanjutnya menggunakan teknik analisis domain.

\section{HASIL}

\section{Karakteristik responden}

Karakteristik dokter pada penelitian ini. Status demografi responden dikategorikan berdasarkan usia, jenis kelamin, lama bekerja, pendidikan terakhir (akademik dan profesi), serta status kepegawaian. Dapat dilihat bahwa Kelompok usia 25-36 tahun memiliki jumlah terendah yaitu 6 orang $(13,6 \%)$. Selanjutnya, tampak bahwa responden dengan jenis kelamin perempuan memegang jumlah terbanyak $(72,7 \%)$.

\section{Analisis Univariat Variabel Penelitian}

Distribusi frekuensi variabel pada penelitian ini, yaitu Quality of Work Life (X1), Keterlibatan Dokter (X2), Kompensasi yang seimbang (X3), Rasa Aman terhadap Pekerjaan (X4), Keselamatan Lingkungan Kerja (X5), Rasa Bangga terhadap Institusi (X6), Pengembangan Karir (X7), Fasilitas yang Tersedia (X8), Penyelesaian Masalah (X9), Komunikasi (X10) dan Kinerja Dokter (Y1). Dapat dilihat bahwa dari 44 responden, sebagian besar dokter di Rumah Sakit Umum Daerah Syekh Yusuf berada pada kategori QWL yang tinggi (75\%). Sementara, sebanyak 32 dokter $(72,7 \%)$ memiliki kinerja yang baik.

\section{Analisis Bivariat}

Tabel 1 menunjukkan hubungan antar-variabel, dimana didapatkan bahwa Quality of Work Life, Kompensasi yang Seimbang, Rasa Aman terhadap Pekerjaan, Keselamatan Lingkungan Kerja, dan Rasa 
Bangga terhadap Institusi memiliki Sementara lima variabel lainnya tidak. hubungan bermakna dengan kinerja dokter.

Tabel 1. Hasil uji fisher variabel independen terhadap variabel dependen di RSUD Syekh Yusuf Kabupaten Gowa, tahun 2017

\begin{tabular}{clc}
\hline No. & \multicolumn{1}{c}{ Variabel Penelitian } & p \\
\hline 1 & Quality of Work Life*Kinerja Dokter & 0,001 \\
2 & Keterlibatan Dokter*Kinerja Dokter & 1,000 \\
3 & Kompensasi yang Seimbang*Kinerja Dokter & 0,001 \\
4 & Rasa Aman terhadap Pekerjaan*Kinerja Dokter & 0,032 \\
5 & Keselamatan Lingkungan Kerja*Kinerja Dokter & 0,027 \\
6 & Rasa Bangga terhadap Institusi*Kinerja Dokter & 0,048 \\
7 & Pengembangan Karir*Kinerja Dokter & 0,247 \\
8 & Fasilitas yang Tersedia*Kinerja Dokter & 0,161 \\
9 & Penyelesaian Masalah*Kinerja Dokter & 0,175 \\
10 & Komunikasi*Kinerja Dokter & 0,105 \\
\hline
\end{tabular}

Sumber: Data Primer, tahun 2017

Tabel 2. Hasil Uji Multivariat Variabel Penelitian pada Dokter di RSUD Syekh Yusuf Gowa, Tahun 2017

\begin{tabular}{lrrrr}
\hline \multicolumn{1}{c}{ Variabel } & \multicolumn{1}{c}{ B } & \multicolumn{1}{c}{ Wald } & P & \multicolumn{1}{c}{ Exp (B) } \\
\hline Kompensasi seimbang & 3,133 & 6,920 &, 009 &, 044 \\
Rasa aman terhadap pekerjaan &, 518 &, 105 &, 746 & 1,678 \\
Keselamatan lingkungan kerja & $-1,259$ & 1,401 &, 237 &, 284 \\
Rasa bangga terhadap institusi & $-23,474$ &, 000 &, 999 &, 000 \\
\hline Constant & 3,874 & 10,268 &, 001 & 48,157 \\
\hline
\end{tabular}

Sumber: Data Primer, tahun 2017

\section{Analisis Multivariat}

Tabel 2 menunjukkan besar dan arah pengaruh Kompensasi yang seimbang (X3), Rasa Aman terhadap Pekerjaan (X4), Keselamatan Lingkungan Kerja (X5), Rasa Bangga terhadap Institusi (X6) terhadap Kinerja Dokter (Y1). Penelitian ini mendapatkan bahwa secara bersama-sama keempat variabel yang diujikan mempengaruhi kinerja dengan arah positif, namun secara parsial hanya variabel

\section{PEMBAHASAN}

Hasil penelitian ini memperlihatkan Quality of Work Life (QWL) berhubungan signifikan dengan kinerja dokter yang berarti bahwa semakin tinggi QWL dokter pelayanan medik di RSUD Syekh Yusuf Kabupaten Gowa maka semakin baik pula kinerja dokter di RSUD Syekh Yusuf Kabupaten Gowa, begitupun sebaliknya.

QWL adalah persepsi pegawai mengenai keadaan fisik dan mental dalam bekerja. Dengan memberikan perhatian kepada tingkat QWL karyawan dapat membuat karyawan merasa kebutuhannya kompensasi yang seimbang yang memiliki pengaruh positif terhadap kinerja dokter.

\section{Hasil Wawancara Mendalam}

Hasil analisis data kuantitatif dan data kualitatif yang didapatkan pada penelitian ini. Berdasarkan data yang didapatkan, secara umum persepsi dokter mengenai komponen QWL sudah baik, namun masih ada beberapa hal yang perlu ditingkatkan, seperti pelaksanaan program K3.

terpenuhi sehingga terjadi peningkatan kinerja sebagai hasilnya (Cascio, 2006).

Adanya hubungan secara parsial antara kompensasi yang seimbang, rasa aman terhadap pekerjaan, keselamatan lingkungan kerja, dan rasa bangga terhadap institusi terhadap Kinerja Dokter, menunjukan bahwa semakin tinggi persepsi dokter pada salah satu aspek tersebut maka semakin baik pula kinerja dokter di RSUD Syekh Yusuf Kabupaten Gowa, begitupun sebaliknya.

Menurut Gavin dan Vinten (2005), kompensasi yang diberikan perusahaan 
akan berdampak pada kinerja pekerja dan mendorong tingkat kepuasaan yang dirasakan oleh pekerja sehingga hal tersebut mendukung temuan pada penelitian ini.

Studi yang mendukung temuan pada penelitian ini lainnya adalah Simanungkalit (2012) yang menyatakan bahwa persyaratan agar karyawan mempunyai rasa aman di dalam pekerjaannya yaitu suasana kerja itu dirasakan sebagai suasana tanpa ada ancaman, ancaman bahwa sebagai karyawan tidak akan dipecat semena-mena tanpa ada alasan yang masuk akal, juga suasana yang dimengerti oleh atasan, serta ancaman fisik maupun hukum pidana. Tercapainya rasa aman tersebut akan berdampak pada kinerja dan motivasi kerja karyawan.

Studi lain yang mendukung temuan di atas adalah Rai dan Tripathi (2015) yang mengemukakan bahwa lingkungan kerja yang aman dan nyaman akan meningkatkan kinerja. Lingkungan kerja yang dimaksud memiliki arti lebih luas yaitu faktor karakteristik organisasi yang terdiri atas lingkungan sosial dan nonsosial, meliputi sarana dan prasarana. Sementara itu, rasa bangga terhadap institusi memiliki hubungan positif dan keeratannya kuat terhadap motivasi perawat untuk bekerja lebih produktif dan pada akhirnya kinerja (Samtica, 2011).

Berdasarkan informasi yang diperoleh dalam wawancara mendalam, didapatkan bahwa secara umum dokter di RSUD Syekh Yusuf Gowa memiliki persepsi yang cukup baik akan kehidupan kerjanya. Namun, masih terdapat beberapa hal yang perlu diperbaiki terutama pada aspek penyelenggaraan K3RS, penyediaan fasilitas yang memenuhi standar pelayanan,

\section{DAFTAR PUSTAKA}

Aketch et al. (2012). Effects of quality of work life on job performance: theoritical perspective and literature review. Current Research Journal of Social Sciences, 4(5): 383-388 sistem reward and punishment serta beban kerja yang bagi beberapa responden dirasa terlalu berat.

Secara khusus, pihak manajemen RSUD Syekh Yusuf Gowa belum memiliki program yang dibuat untuk meningkatkan QWL karyawan. Namun secara parsial dapat ditemukan program maupun kebijakan RS yang berkenaan dengan QWL maupun komponennya, seperti keterlibatan dokter dalam rapat, pemberian wewenang dalam bentuk kewenangan klinis, sistem penyelesaian masalah yang bertahap dan bersifat kekeluargaan, serta jalur komunikasi, salah satunya dengan adanya grup WhatsApp Messenger.

\section{KESIMPULAN DAN SARAN}

Dari hasil penelitian yang dilakukan menunjukkan bahwa terdapat hubungan yang signifikan antara Quality of Work Life (QWL), kompensasi yang seimbang, rasa aman terhadap pekerjaan, keselamatan lingkungan, dan rasa bangga terhadap institusi terhadap kinerja dokter: perhatian oleh pihak manajemen dalam upaya meningkatkan aspek tersebut dapat berakibat pada peningkatan kinerja dokter. Komponen QWL yang paling mempengaruhi kinerja dokter adalah kompensasi. Suasana ideal yang dapat meningkatkan kinerja dokter ialah harus didukung dengan sarana dan prasana yang baik, dijembatani dengan komunikasi yang baik dan kebijakan-kebijakan yang paten serta tersosialisasi dengan baik. Diharapkan dengan adanya perhatian dari pihak manajemen pada aspek-aspek tersebut guna meningkatkan persepsi dokter, dapat meningkatkan kinerja dokter di RSUD Syekh Yusuf Kabupaten Gowa.

Asgari M. H., Nojbaee S. S. \& Rahnama O. (2012). The Relationship between quality of work life and performance of Tonekabon Guidance Schools teachers. Journal of Basic and 
Applied Scientific Research, 2(3): 2569-2575

Ayuningtyas D. \& Suherman R. (2008). Hubungan kinerja bidan dalam penatalaksanan antenatal care dengan quality of wok life di Kota Tasikmalaya tahun 2007. Jurnal Manajemen Pelayanan Kesehatan, 11: $179-84$

Baltazar et al .(2015). Quality of work life and mental health in primary care physicians. Elsevier Procedia Social and Behavioral Sciences, 3: 4935-4940

Battu N., \& Chakravarthy. (2014). Quality of Work Life of Nurses and Paramedical Staff in Hospitals. International Journal of Business and Administration Research Review, 2(4): 200-207

Cahyani A.S. (2014). Analisis pengaruh kepuasan kerja terhadap kinerja dokter di ruang rawat inap Rumah Sakit Umum Daerah Jayapura (Tesis). Makassar: Universitas Hasanuddin.

Campbell JP. (1990). Modeling the performance prediction problem in industrial and organizational psychology. Dalam: Dunnette MD, Hough LM editor. Handbook of Industrial and Organizational Psychology. Palo Alto, CA: Consulting Psychologists. Press:687-732

Cascio W.F. (2006). Managing human resources, productivity, quality of work life, profit, 7th ed. New York: Mc Graw-Hill.

Duyan et al. (2013). Measuring work related quality of life and affective well-being in Turkey. Mediterranean Journal of Social Sciences, 4.

Elisaveta S. (2006). Relationship among perception of quality of work life and job satisfaction. Management and Organizational Review, 2(3):459- 460

Hafizurrachman, Trisnantoro L. \& Bachtiar A. (2011). Kesehatan dan kualitas kehidupan kerja terhadap kinerja perawat di rumah sakit umum tangerang. National Public Health Journal, 6(2): 59-66

Hassan G. (2013). The relationship between QWL and job satisfaction: A survey of human resource managers in Iran. Interdisciplinary Journal of Contemporary Research in Business, 5 (8).

Hatam N. et al .(2014). The relationship between quality of work life and human resource productivity in knowledge workers. Journal of Health Management \& Informatics, 1(3): 59-65

Khan M.R. \& Zia-ud-Din. (2010). The impact of organizational commitment on employees job performance: 'a study of oil and gas sector of Pakistan'. Pakistan Journal (serial online) Jan-Mar diunduh 22 September 2017. Available from: URL:

HYPERLINK http://dx.doi.org/10.2139/ssrn.15705 44

Koopmans L, et al. (2011). Conceptual framework of individual work performance: a systematic review. American College of Occupational and Enviromental Medicine, 53: 856-866

Kubendra V., Muthukumar S. \& Priyadharshini.M. (2013). Impact of quality of work life on the performance of the employees in it organisations. Indian Journal of Economics and Development, 1(3): $82-85$

Nayak T. \& Kumar. (2015). Quality of Work Life and Organizational Performance: The Mediating Role of Employee Commitment. Journal of Health Management, 17(3): 263273

Parsa B. et al. (2014). Relationship between quality of work life and career advancement among Iranian academics. Elsevier Procedia Social and Behavioral Sciences, 152: 108-111 
Pratama MY. (2012). Pengaruh quality of work life terhadap kinerja perawat pelaksana di Rumah Sakit TK II Putri Hijau Kesdam I/BB Medan (Tesis). Medan: Universitas Sumatera Utara.

Pratiwi K. \& Himam F. (2014). Kualitas kehidupan kerja ditinjau dari kepuasan kerja dan persepsi terhadap kinerja. Jurnal Psikologi Undip, 13 (1): $42-49$

R.Gayathiri \& Dr. Lalitha Ramakrishnan (2013). Quality of Work Life Linkage with Job Satisfaction and Performance. International Journal of Business and Management Invention, 2(1): 1-8

Rai \& Tripathi. (2015). A study on QWL and its effects on job performance. Journal of Management Sciences and Technology, 2(2): 33-42.

Samtica. (2011). Hubungan komponen kualitas kehidupan kerja (quality of work life) dengan motivasi kerja perawat pelaksana di RS Haji Jakarta tahun 2011. National Public Health Journal, 6(3) : 55-60

Sari N. (2014). Analisis pengaruh kulaitas kehidupan kerja terhadap komitmen organisasi perawat pelaksana di Rumah Sakit Universitas Hasanuddin. (Tesis). Makassar: Universitas Hasanuddin.

Selahattin K. \& Omer S. (2012). An empirical research on relationship quality of work life and work engagement. Elsevier Procedia Social and Behavioral Sciences, 62: 360-366

Shahbazi B. et al. (2011). A Survey of relationship between the quality of work life and performance of Department Chairpersons of Esfahan University and Esfahan Medical Science University. Elsevier Procedia - Social and Behavioral Sciences, 30: 1555-1560

Sheel S. et al. (2012). Quality of work life, employee performance and career growth opportunities. International
Journal of Multidisciplinary

Research, 2(2): 291-300

Simanungkalit E.V. (2012). Analisis kualitas kehidupan kerja karyawan industri garmen di Indonesia (Tesis). Jakarta: Universitas Indonesia.

Sirgy M., Efraty D., Siegel P., \& Lee D.J. (2001). A new measure of quality of working life (QWL) based on need satisfaction and spillover theories. Social Indicators Research, 55 (3): 241-302

Srivastava S, \& Kanpur R. (2014). A study on quality of work life: key elements \& it's implications. IOSR Journal of Business and Management, 16 (3): 54-59.

Swamy D.R, Nanjundeswaraswamy T.S, \& Rashmi S. (2015). Quality of Work Life: Scale Development and Validation. International Journal of Caring Sciences, 8(2): 281-300

Taghavi S., Ebrahimzadeh F., Bhramzadh H. \&Masoumeh H. (2014). A study of the relationship between quality of work life and performance effectiveness of high school teachers' in Shirvan. International Journal of Academic Research in Business and Social Sciences, 4(1): 295-301 